\title{
Treatment requirements of infants with rhesus isoimmunisation within a geographically defined area
}

\author{
A Greenough, G Hartnoll, H Hambley, J Richards
}

Arch Dis Child Fetal Neonatal Ed 2002;87:F202-F203

\begin{abstract}
See end of article for authors' affiliations

Correspondence to: Professor Greenough Department of Child Health, 4th floor, Ruskin Wing, King's College Hospital, London SE5 9RS, UK;

anne.greenough@kcl.ac.uk
\end{abstract}

Accepted 3 May 2002

\begin{abstract}
Objective: To provide population based data on the treatment requirements of infants with rhesus isoimmunisation.

Setting: Twenty nine hospitals in South Thames in which 81119 deliveries occurred between February 1999 and January 2000.

Design: Every month, a clinician identified in each of the hospitals sent back a postcard indicating whether or not an infant with $\mathrm{RhD}$ had required treatment in their institution. Antenatal and postnatal information was then requested from all those who gave positive responses.

Main outcome measures: Requirement for postnatal treatment for rhesus isoimmunisation.

Results: During the one year study period, only 26 infants required treatment for rhesus isoimmunisation. The median duration of phototherapy of the 26 infants was five days (range 1-12). Seven infants required at least one exchange transfusion (two required two exchange transfusions), and seven infants received one "top up" transfusion. None received erythropoietin and no infant died.

Conclusion: The results suggest that few infants require treatment for rhesus isoimmunisation.
\end{abstract}

T he introduction of anti-D prophylaxis to prevent sensitisation of women lacking rhesus antigens resulted in an appreciable reduction in the incidence of rhesus isoimmunisation, with a current estimate of 10.6 cases per 10000 live births. ${ }^{1}$ The perinatal death rate was also reduced, from 15 per 10000 births reported in $1963^{2}$ to 0.54 per 10000 births reported in 1983. The latter figure, however, is an underestimate of the true situation, as it does not include termination of pregnancy for severe $\mathrm{Rh}$ disease and spontaneous fetal losses before 28 weeks of gestation. ${ }^{3}$ Postnatal and sensitising event prophylaxis with anti-D is now undertaken. Almost $90 \%$ of the sensitisation that follows delivery can be prevented by administration of anti-D at delivery, but a residual level of D sensitisation occurs. Up to $2 \%$ of RhD negative women show evidence of antibody production despite prophylaxis. ${ }^{3}$ Antenatal administration of anti-D (500 IU of anti-D) at 28 and 34 weeks has been recommended in addition to current practices, as this would prevent isoimmunisation for virtually all non-sensitised RhD negative women. ${ }^{4}$ This, however, would require a fourfold increase in hyperimmune anti-D production with associated costs. ${ }^{5}$ Whether such an approach would be cost effective in the United Kingdom requires accurate information on the current outcome of infants with Rh disease. The aim therefore of this study was to undertake a prospective, population based survey of the treatment requirements of infants with rhesus isoimmunisation.

\section{METHODS}

Data were collected on all infants with rhesus D isoimmunisation (that is direct Coomb's test positive infants born to Rh negative mothers) who were born within a geographically defined area during a 12 month period (February 1999 to January 2000 inclusive) and required postnatal treatment. Clinicians were identified at 29 hospitals in which deliveries occurred in South Thames (see Acknowledgments). The total live births at the hospitals during the study period was 81 119; about one sixth were to Rh negative women. Additional antenatal prophylaxis with anti $\mathrm{D}$ in the last trimester of pregnancy was not given during the study period in South Thames. Every month, each clinician was requested to send to the data collecting centre (the neonatal intensive care unit at King's College Hospital) a postcard on which they indicated whether or not an infant with Rh disease had been delivered in their institution. Antenatal and postnatal outcome data were then requested from all those who gave positive results. From one hospital only were these data collected retrospectively. The data requested included: mother's address, previous pregnancy outcomes, whether anti-D had been administered, and the number of intrauterine transfusions during the current pregnancy. In addition, information was requested on the gestational age at delivery, the duration of phototherapy, the requirement for exchange transfusion(s) and/or top up transfusions, whether the infant had received erythropoietin, and if the infant had died. Within the study period, late responders were chased, and, at the end of the year, each hospital was sent a summary of their results and requested to confirm its accuracy. Only the outcome of infants who required treatment for rhesus isoimmunisation and whose mothers were South Thames residents are reported.

\section{RESULTS}

During the 12 month period, 26 infants with Rh disease had at least received phototherapy. Only one of the 26 mothers was a primigravida. The data on anti-D administration in previous pregnancies were available in 14 cases; anti-D had not been given after three miscarriages and two terminations of pregnancy. Five of the 26 infants had undergone between two and 10 in utero transfusions. The 26 infants required a median duration of phototherapy of five days (range 1-12). Seven infants required at least one exchange transfusion, and two required two exchange transfusions. No infant received erythropoietin. Seven infants required one top up transfusion at a median age of 3 weeks (range 2 days to 12 weeks). No infant required a second top up transfusion. None of the 26 infants died. Ten infants were born prematurely; their median gestational age at delivery was 36 weeks (range 33-36). One infant was born at 33 weeks gestation, one at 34 weeks, and two at 35 weeks. The infant born at 33 weeks gestation required phototherapy for only one day, no exchange transfusion, and one top up transfusion at 14 days after birth. The 
infant born at 34 weeks gestation required one exchange and one top up transfusion and 12 days of phototherapy.

\section{DISCUSSION}

In this population based survey over a 12 month period in which there were 81119 live births, only 26 infants required treatment for Rh disease and no infant died. Deaths attributable to Rh haemolytic disease were reported in 1994 to be 1.3 per 100000 live births. ${ }^{6}$ It has been suggested that the true death rate is closer to six deaths per $100000,{ }^{7}$ as certification data exclude abortions and five times as many deaths were uncertified as certified by the General Register Office in Scotland. ${ }^{7}$ Our survey only included live births, and thus we cannot comment on the total fetal and infant death rate attributable to rhesus isoimmunisation. The data, however, have the strength of being prospectively collected and population based, thus giving an accurate reflection of infant mortality. In a survey performed in Northern Ireland over a 30 month period and including about 65000 deliveries, there was only one neonatal death. ${ }^{8}$ These and our data suggest that the current neonatal mortality from Rh disease is low.

It has been highlighted ${ }^{9}$ that a large proportion of the cost related to rhesus isoimmunisation is the cost of neonatal intensive care. We therefore prospectively documented treatment requirements of infants with Rh disease. We did not collect information on infants who did not require treatment as such infants would have no extra financial implications. In this population based survey, we found that 26 infants required treatment-that is, $0.03 \%$ of the live births surveyed. It is possible that infants who received phototherapy exclusively on the postnatal wards may have been missed, but we think that this is unlikely because in 28 of the 29 hospitals we recorded the data prospectively on a monthly basis. In addition, at the end of each year all the clinicians were sent a list of treated infants in their hospital and were asked to cross check their records for the whole year. In a previously published survey of the outcome of RhD antibody affected pregnancies in Northern Ireland, ${ }^{8}$ there were 59 neonatal unit admissions for rhesus isoimmunisation; 29 of the infants required exchange transfusion and 55 required phototherapy. That survey was carried out over a 30 month period during which time there were about 65000 deliveries. These data therefore also suggest that, compared with the number of live births, only a small proportion of infants require neonatal treatment for rhesus isoimunisation. Nevertheless, the treatment requirements of the infants who are rhesus isoimmunised may be substantial. In comparison with our data, a greater proportion of the total live births in Northern Ireland required neonatal admission and treatment because of rhesus isoimmunisation. ${ }^{8}$ There are differences in the two surveys. We performed a prospective study during the year 2000, whereas they surveyed births, probably retrospectively from September 1994 to February 1997. In addition, 26\% of their planned deliveries occurred in hospital without paediatric cover, whereas there were no such deliveries in the live births that we surveyed.

Although the data in our study on anti-D administration were incomplete, in five cases there had been failure to administer anti-D after miscarriage or termination of pregnancy. Thus it remains essential to continue to remind clinicians of the criteria for, and importance of, anti-D administration. Strict adherence to the guidelines for administration of anti-D prophylaxis would reduce the sensitisation rate.

\section{ACKNOWLEDGEMENTS}

Collaboration between the Directors of Public Health and the neonatal subgroup of the South East Thames (SET) Perinatal Monitoring Group led to the development of this audit. We thank the SET Perinatal Monitoring Group for providing the financial support for this study, and Ms Sue Williams for secretarial assistance. We are particularly grateful to the following clinicians for collecting the data:

Dr N Aiton, Royal Sussex County Hospital, Brighton

Dr S Al Jawad, Kingston Hospital

Dr B Al-Rubeyi, Greenwich District Hospital

Dr H Ali and Dr J J Bowyer, St Peter's Hospital, Chertsey

Dr A Bedford-Russell, St George's Hospital, Tooting, London

Dr S A J Bokhari, Queen Mary's Hospital, Sidcup

Mrs S Cavanagh and Dr E Wearmouth, District General Hospital, Eastbourne

Dr Y L J Chang, Mayday Hospital, Croydon

Dr D Cook, Queen Elizabeth the Queen Mother Hospital, Margate

Dr P Day, Pembury Hospital

Dr D A Ducker, Medway Maritime Hospital, Gillingham

Dr M Evans, Royal Surrey County Hospital, Guildford

Dr G Fox, Guy's Hospital

Dr A Garg, Worthing Hospital

Mrs D Garland and Dr C Unter, Maidstone Hospital

Dr S Hannam, King's College Hospital, London

Dr K Haque, Queen Mary's (St Helier) Hospital for Children, Carshalton

Dr Al Hilaly, East Surrey Hospital, Redhill

Dr M Katugampola, Epsom General Hospital

Dr L Lamont, St Richard's Hospital, Chicester

Dr T Y D Leung, Gravesend and North Kent Hospital

Dr I Lewis Crawley Hospital

Dr A Long, Farnborough Hospital

Dr D Long, Kent and Canterbury Hospital

Professor A D Milner, St Thomas' Hospital, London

Dr V Shah, William Harvey Hospital, Ashford

Dr G Whincup, Conquest Hospital, St Leonards on Sea

\section{................}

Authors' affiliations

A Greenough, Department of Child Health, King's College Hospital, London, UK

G Hartnoll, University Hospital, Lewisham, UK

H Hambley, Welsh Blood Service, Pontyclun, Wales

J Richards, Department of Public Health-Clinical Audit, West Kent Health Authority, Aylesford, Kent, UK

\section{REFERENCES}

1 Greenough A. Rhesus disease: postnatal management and outcome. Eur J Pediatr 1999;158:689-93.

2 Butler NR, Bonham DG. Perinatal mortality: the first report of the 1958 British Perinatal Morality Survey. Edinburgh: Churchill, 1963.

3 Boswell PJ, MacKenzie IZ, Entwistle CC. Deaths from rhesus haemolytic disease. BM 1985:291:1351-2.

4 Mollison PL, Engelfreit CP, Contreras M. Blood transfusion in clinical medicine. 10th ed. Oxford: Blackwell Scientific Publications, 1993.

5 Selinger M. Immunoprophlaxis for rhesus disease: expensive but worth it? BrJ Obstet Gynaecol 1991;98:509-12.

6 Clarke C Hussey RMSO. Decline in deaths from rhesus haemolytic disease of the newborn. J R Coll Physicians Lond 1994;28:310-11.

7 Whitfield CR, Raffat A, Urbaniak S. Underreporting of mortality from $\mathrm{RhD}$ haemolytic disease in Scotland and its implications: retrospective review. BMU 1997;315:1504-5.

8 Craig S, Morris K, Tubman T, et al. The fetal and neonatal outcomes of Rhesus D antibody affected pregnancies in Northern Ireland. Ir Med J 2000;93:17-18.

9 Baskett FT, Parson ML. Prevention of rhesus (D) allo immunization: a cost benefit analysis. Can Med Assoc J 1990;142:337-9. 